\title{
Penipuan Sebagai Hasil Manipulasi Dunia Maya di Indonesia
}

\author{
Abdul Azizun Nafi ${ }^{1}$, Naufal Tsabit ${ }^{2}$, Nur Aini Rakhmawati ${ }^{3}$, Regita Ayu Cahyani Zulaikhah ${ }^{4}$, \\ Ufaira Khanzahasna Nanfaiq Nadhifa ${ }^{5}$ \\ Departemen Sistem Informasi, Fakultas Teknologi Informasi dan Komunikasi, Institut Teknologi \\ Sepuluh Nopember \\ Email: ${ }^{1}$ abdul.azizun15@mhs.is.its.ac.id, ${ }^{2}$ naufal16@mhs.is.its.ac.id, ${ }^{3}$ iin@is.its.ac.id, \\ ${ }^{4}$ regita16@mhs.is.its.ac.id, ${ }^{5}$ ufairakhanzahasna16@mhs.is.its.ac.id
}

\begin{abstract}
The presence of social media provides a lot of information, ranging from the ease of exchanging messages and information, to users who want to publish their work in order to be acknowledged by people, eliminate restrictions and can expand interchangeable discourse. Ideally, interactions that occur between individuals are based on individuals against other individuals because each one will not involve anything harmful. Through research conducted in the context of social media, it is hoped that people will have a more comprehensive understanding of social media in their lives and how to be decent. This study aims to find out how situations can be carried out in social interactions in society that use social media.
\end{abstract}

Keywords: Social Media, fraud, cyberspace manipulation

\begin{abstract}
Abstrak. Kehadiran media sosial juga memberikan begitu banyak kemudahan, mulai dari mudahnya bertukar pesan dan informasi, sampai pada kemudahan seorang pengguna yang ingin mempublikasikan karyanya agar dapat diketahui orang lain, menghilangkan batasan generasi dan memperluas wacana yang dapat dipertukarkan. Idealnya, interaksi yang terjadi di antara individu dilakukan berdasarkan kepercayaan individu tersebut terhadap individu lainnya bahwa masing-masing tidak akan berbuat sesuatu yang merugikan. Melalui penelitian mengenai peristiwa yang terjadi dalam interaksi sosial melalui media sosial, diharapkan masyarakat memiliki pemahaman yang lebih komprehensif mengenai dampak kehadiran media sosial di dalam kehidupan mereka dan bagaimana bersikap terhadap dampak tersebut. Penelitian ini bertujuan untuk memahami bagaimana peristiwa penipuan dapat terjadi pada interaksi sosial maya dalam masyarakat berjejaring yang berinteraksi menggunakan media sosial.
\end{abstract}

Kata Kunci: Media Sosial, penipuan, manipulasi dunia maya

\section{Pendahuluan}

Lahirnya media sosial dengan fasilitas teknologi yang lengkap membuat penggunanya dapat berkomunikasi dengan pengguna lain yang secara geografis berjauhan, namun seolah-olah mereka berada pada jarak yang dekat. Kehadiran media sosial juga memberikan begitu banyak kemudahan, mulai dari mudahnya bertukar pesan dan informasi, sampai pada kemudahan seorang pengguna yang ingin mempublikasikan karyanya agar dapat diketahui orang lain, menghilangkan batasan generasi dan memperluas wacana yang dapat dipertukarkan. Media sosial juga sudah banyak berperan dalam bidang ekonomi dan perdagangan dengan kemampuannya mendukung kegiatan pemasaran produk sampai pada kegiatan jual beli.

Namun penelitian menemukan bahwa interaksi yang dilakukan oleh masyarakat berjejaring dengan menggunakan teknologi Internet berdampak pada munculnya anggota masyarakat yang kurang bertanggung jawab dan mengucilkan diri dari interaksi dengan masyarakat (Levine, 2001 dalam Kollanyi, 2007). Orang - orang ini kemudian berperilaku menyimpang dari norma interaksi sosial maya dengan melakukan tindakan yang mengganggu interaksi sosial yang terjadi. Beberapa tindakan 
menyimpang adalah melakukan perusakan pada alur media (hacking), pencurian data anggota jaringan sosial, dan penipuan (deception) yang dilakukan untuk mendapatkan keuntungan pribadi.

Peristiwa penipuan harus menjadi perhatian karena tindakan itu memiliki pengaruh yang sangat besar bagi kehidupan sosial korban dan perlu dicari metode pencegahannya karena keberadaan media sosial sudah menjadi bagian tak terpisahkan dari kehidupan sosial, dan dipercayai sebagai salah satu pendukung interaksi sosial dalam kehidupan sehari-hari. Di Indonesia sampai tahun 2012 tercatat pengguna Facebook sebanyak 65 juta orang (Harian TI, 15 November 2013), sedangkan media sosial LINE mencatat 14 juta pengguna di Indonesia (Harian TI, 10 Desember 2013), sementara itu pada penggunaan media sosial Twitter, Indonesia menduduki peringkat kedua terbanyak di dunia (Tribunnews, 6 Oktober 2013).

Idealnya, interaksi yang terjadi di antara individu dilakukan berdasarkan kepercayaan individu tersebut terhadap individu lainnya bahwa masing-masing tidak akan berbuat sesuatu yang merugikan. Terjadinya peristiwa penipuan dalam interaksi melalui media sosial ini menunjukkan bahwa terdapat tindakan oleh pelaku penipuan yang memanfaatkan kepercayaan yang diberikan oleh korban penipuan dalam mempersepsi tawaran dan ajakan yang diberikan oleh pelaku selama interaksi berlangsung.

Dalam interaksi tatap muka (face to face interactions) maupun melalui media (mediated interaction) terdapat pelaku yang menyatakan atau menawarkan sesuatu atau mengajak berbuat sesuatu yang disampaikan dalam bentuk lambang yang maknanya disepakati oleh semua pihak yang berinteraksi sehingga dapat menciptakan pemahaman yang sama tentang hal yang dipertukarkan dalam interaksi. Terjadinya peristiwa penipuan seperti janji untuk menikahi yang dilakukan seorang pria dalam interaksi melalui media sosial Facebook menunjukkan adanya tindakan rekayasa lambang yang dilakukan oleh pelaku penipuan agar korban tidak menyadari bahwa ada lambang yang sengaja digunakan oleh penipu untuk membuatnya mempersepsi bahwa semua pernyataan, tawaran atau ajakan yang diterimanya adalah benar dan menganggap bahwa pelaku bertujuan membantu atau memberinya keuntungan.

Melalui penelitian mengenai peristiwa yang terjadi dalam interaksi sosial melalui media sosial, diharapkan masyarakat memiliki pemahaman yang lebih komprehensif mengenai dampak kehadiran media sosial di dalam kehidupan mereka dan bagaimana bersikap terhadap dampak tersebut. Berdasarkan latar belakang ini maka penelitian dirumuskan dalam sebuah pertanyaan: "Bagaimana peristiwa interaksi antara korban penipuan dan pelaku penipuan melalui media sosial dapat mengakibatkan terjadinya tindakan manipulasi?"

Penelitian ini bertujuan untuk memahami bagaimana peristiwa penipuan dapat terjadi pada interaksi sosial maya dalam masyarakat berjejaring yang berinteraksi menggunakan media sosial.

\section{Tinjauan Pustaka}

Penggunaan media sosial yang sudah sangat meluas ini kemudian membentuk sebuah interaksi sosial baru berupa Jejaring Sosial (Social Network) yang merupakan sebuah struktur sosial yang dibentuk oleh individu (atau kelompok) yang terhubungkan oleh satu atau lebih saling ketergantungan, seperti persahabatan, persaudaraan, kepentingan bersama, petukaran perdagangan, ketidak sukaan, berpacaran, kesamaan keyakinan, pengetahuan atau prestise (Simmel, 1955, White, Boorman, and Brieger 1976, dalam Pescoslido, 2006). Andreas Kaplan dan Michael Haenlein mendefinisikan media sosial sebagai "sebuah kelompok aplikasi berbasis internet yang membangun di atas dasar ideologi dan teknologi Web 2.0, dan yang memungkinkan penciptaan dan pertukaran user-generated content". Pesatnya perkembangan media sosial dipicu oleh perasaan orang-orang yang seperti bisa memiliki media sendiri. Jika untuk memiliki media tradisional seperti televisi, radio, atau koran dibutuhkan modal yang besar dan tenaga kerja yang banyak, maka lain halnya dengan media. Seorang pengguna 
media sosial bisa mengakses menggunakan media sosial dengan jaringan internet bahkan yang aksesnya lambat sekalipun tanpa perlu mengeluarkan biaya besar, alat mahal dan dilakukan sendiri tanpa karyawan. Pengguna media sosial dapat dengan bebas bisa mengubah, menambahkan, memodifikasi baik tulisan, gambar, video, grafis, dan berbagai model konten lainnya.

Penipuan adalah sebuah tindakan seseorang atau sekelompok orang membuat kesan bahwa sesuatu itu benar dan tidak palsu untuk membuat orang lain memberikan kepercayaan. Secara formal, penipuan didefinisikan sebagai tindakan "membujuk orang lain dengan tipu muslihat, rangkaian katakata bohong, nama palsu, keadaan palsu agar memberikan sesuatu" (Anwar, 1979, hal. 16). Penipuan secara online pada dasarnya sama dengan penipuan konvensional. Hal yang menjadi pembeda adalah pada sarana perbuatannya yakni menggunakan sistem elektronik (komputer, internet, perangkat telekomunikasi). Sehingga secara hukum, penipuan secara online dapat diperlakukan sama sebagaimana delik konvensional yang diatur dalam Kitab Undang-Undang Hukum Pidana ("KUHP”). Penipuan secara online juga bisa dijerat menggunakan UU No. 11 Tahun 2008 tentang Informasi dan Transaksi Elektronik (UU ITE).

\section{Analisis}

Keberadaan dunia maya telah dimanfaatkan oleh orang-orang tidak bertanggung jawab dengan memanipulasi berbagai informasi yang ada untuk melakukan penipuan ataupun pencemaran nama baik. Penipuan dan pencemaran nama baik sudah sering dilakukan dari sebelum adanya akses dunia maya. Dengan berkembangnya teknologi, tidak diragukan lagi bahwa kasus penipuan semakin marak. Hal ini terjadi karena dengan adanya dunia maya, penipu sangat sulit untuk dilacak oleh pihak kepolisian. Selain itu barang bukti penipuan dapat dengan mudah dihapus dan dihilangkan. Meskipun penegak hukum sudah menyusun strategi untuk menangkap para pelaku penipuan seperti :

\section{a. Pre-emptive}

Melakukan pencerdasan kepada masyarakat dan pelatihan khusus bagi pihak aparat keamanan

b. Pre-eventive

Memantau lalu lintas transaksi dunia usaha dan mengawasi transaksi yang mencurigakan

\section{c. Repressive}

Menghukum pidana supaya jera dan tidak melakukan aksi penipuan

Menurut Christiany Juditha, dalam mendekati korban, pelaku love scam melakukan tiga tahap pola komunikasi, yaitu:

\section{a. Impersonal}

Dalam tahap ini pelaku menceritakan hal pribadi agar menimbulkan kedalaman pada hubungan yang sedang dijalin. Dengan itu hubungan menjadi cepat akrab dan intim

b. Interpersonal

Tahap ini penipu berupaya untuk mengubah perilaku, sifat, dan juga pendapat korban. Disini pelaku dan korban saling berkomunikasi, lalu korban secara perlahan terpengaruh dengan perkataan sang penipu.

\section{c. Hyperpersonal}

Pada tahap ini korban merasa lebih nyaman untuk mengobrol menggunakan media sosial daripada bertemu pandang. Hal ini memudahkan penipu untuk melakukan aksinya.

Menurut Retno Kumalasari, ada dua hal yang dapat dilakukan dengan mudah untuk menghindari penipuan melalui dunia maya :

a. Berpikir Rasional

Lebih teliti dan berhati-hati. Dan jangan dengan mudahnya terbutakan dengan sesuatu yang orang lain tawarkan. Karena hal itu hanya digunakan untuk mengelabui orang 


\section{b. Mendengarkan opini orang lain}

Sebelum melakukan sesuatu yang mungkin merugikan, dengarkan opini dari teman atau keluarga.

Karena opini mereka dapat bersifat subjektif terhadap hal yang ditawarkan seseorang.

Dengan adanya dunia maya obrolan yang kita unggah ke internet dapat langsung tersebar dengan sangat cepat. Oleh karena itu kasus pelecehan nama baik sering menjadi sorotan bagi masyarakat indonesia.

Berbeda dengan penipuan, kasus pencemaran nama baik jauh lebih rumit dari penipuan biasa. Pasalnya, pencemaran nama baik susah dibedakan dengan hak kebebasan berpendapat yang dimiliki oleh setiap manusia. Hal ini dikarenakan tidak adanya batasan yang tegas yang diatur pada peraturan perundang-undangan antara dua tindakan tersebut. Pencemaran nama baik pun mengundang banyak perdebatan dari kalangan masyarakat banyak

Kebebasan berpendapat dibahas pada Pasal 1 angka 1 Undang-undang No. 9 Tahun 1998 tentang Kemerdekaan Menyampaikan Pendapat di Muka Umum berbunyi "Kemerdekaan menyampaikan pendapat adalah hak setiap warga negara untuk menyampaikan pikiran dengan lisan, tulisan, dan sebagainya secara bebas dan bertanggung jawab sesuai dengan ketentuan peraturan perundang-undangan yang berlaku" yang kemudian dijelaskan lebih lanjut di Pasal 5 undang undang No. 9 tahun 1998 bahwa secara bebas yang dimaksud adalah mengeluarkan pendapat, pandangan, kehendak, atau perasaan yang bebas dari tekanan fisik, psikis, atau pembatasan yang bertentangan dengan tujuan.

Sedangkan pencemaran nama baik dijelaskan pada UU ITE Pasal 23 ayat 3 hanya melarang pendistribusian dan/atau pentransmisian informasi elektronik dan/atau dokumen elektronik yang memiliki muatan penghinaan dan/atau pencemaran nama baik. Hanya saja disini masih belum ada penjelasan terkait kriteria yang dapat didefinisikan ke dalam tindakan penghinaan dan/atau pencemaran nama baik.

Secara umum isi dari kedua pasal tersebut mirip antara keduanya, hanya kata "bertanggung jawab" yang berbeda. Namun di pasal tersebut tidak dijelaskan mengenai pengertian dari "bertanggung jawab" tersebut. Hal ini menyebabkan perbatasan kebebasan berpendapat dengan pencemaran nama baik tidak memiliki batasan yang jelas dan tegas.

Seperti pada Kasus Prita Mulyasari pada 24 September 2008 silam dimana Rumah Sakit Omni Internasional, Tangerang menuntut Prita atas email yang telah ditulisnya sebagai pencemaran nama baik seperti yang dimaksud pada Pasal 27 ayat (3) juncto Pasal 1 ayat (1) Undang-undang 11 tahun 2008 tentang Informasi dan Transaksi Elektronik, dan Pasal 310 ayat (2) jucto Pasal 311 ayat (1) KUHP. Awalnya Prita diputuskan kalah pada tanggal 11 Mei 2009 lalu pada 25 Juni 2009 Prita dibebaskan. Lalu pada 30 juni 2011 Prita akhirnya divonis kembali selama 6 bulan penjara atas pengabulan Kasasi Jaksa Penuntut Umum oleh MA.

Meskipun banyak kasus yang menghasilkan perdebatan antara masyarakat, tidak sedikit juga kasus pencemaran nama baik yang pelakunya segera divonis penjara. Seperti kasus MG yang mengunggah foto Walikota Baubau dengan caption "Wibawa Pemimpin kita, datang tidur di tempat kedukaan saat melayat". Pelaku langsung dilaporkan kepada polisi.

\section{Kesimpulan}

Di zaman sekarang, tidak dapat dapat dipungkiri lagi bahwa kita hidup berdampingan dengan teknologi. Perkembangan teknologi yang kian pesat tidak selalu menghasilkan dampak positif, namun memang ada beberapa oknum oknum yang menyalahgunakan teknologi untuk melakukan berbagai macam kejahatan seperti penipuan dan pencemaran nama baik. Kasus penipuan sendiri dapat terjadi saat korban sudah mulai percaya dan termakan setiap perkataan dari para pelaku yang pada faktanya 
semua itu tidak benar. Berbeda dengan penipuan, kasus seperti pencemaran nama baik lebih rumit dan sebenarnya masih mengundang banyak pro kontra sebab beberapa orang merasa bahwa mereka memiliki hak kebebasan untuk berpendapat.

Saat ini memang sudah banyak peraturan dan Undang Undang yang mengatur tentang kejahatan elektronik/melalui dunia maya, namun ada hal hal yang bisa kita lakukan untuk mencegah dan mengurangi jumlah penipuan penipuan di dunia maya, seperti:

a. Jangan mudah percaya terhadap perkataan orang yang baru saja kita kenal melalui dunia maya

b. Mau mendengarkan opini orang lain/orang terdekat sebelum kita berbuat sesuatu karena terkadang kita terbutakan dan tidak bisa berpikir rasional mana yang baik dan mana yang buruk untuk kita.

c. Tidak sembarangan memasukkan informasi data diri pribadi kita ke dalam media sosial dan juga

d. Jangan mudah memberikan informasi pribadi tentang diri kita kepada orang yang baru kita kenal apalagi yang hanya melalui dunia maya

e. Walaupun sudah ada hak kebebasan berpendapat, kita harus tetap bisa memilah mana kata kata yang pantas diucapkan dan mana kata yang tidak. Sebab, kadang dari perkataan kita akan timbul masalah seperti seseorang akan merasa bahwa apa yang kita katakan merupakan bentuk dari pencemaran nama baik.

\section{Referensi}

Anjar Budiarto (05 Juni 2015). Penipuan Media Sosial. https://anjarbudiarto.wordpress.com/2015/06/05/penipuan-media-sosial/. Akses 22 September 2018

Darmayanti, Desak Made Prilia (2015). Kajian Terhadap Tindak Pidana Penipuan Melalui Jual-Beli Online. Denpasar, Open Journal Systems

Detiknews (18 September 2012). Ini Dia Kronologi Prita Mencari Keadilan. https://news.detik.com/berita/2023887/ini-dia-kronologi-prita-mencari-keadilan. Akses 21 September 2018

Fitzpatrick, Neill (2018). Media Manipulation 2.0: The Impact of Social Media on News, Competition, and Accuracy. Canada, Athens Journal of Mass Media and Communications

Forster, Manuel dkk (2014). Trust and Manipulation in Social Networks. France, Nota Di Lavoro. 50

Juditha, Christiany (29 Oktober 2015). Pola Komunikasi dalam Cybercrime (Kasus Love Scam). Makassar, jurnal.kominfo.go.id. 5-9

Kollányi, Bence, (2007). Social Networks and The Network Society. Budapest, Szilárd Molnár - Levente Székely

Kumalasari, Retno (2016). Mencegah Penipuan Jual Beli Online Melalui Perancangan Iklan Layanan Masyarakat. Semarang, Universitas Dian Nuswantoro. 7

Kurnia Athuhema, Daniel (2016).Strategi Kepolisian Dalam Menanggulangi Penipuan yang dilakukan Melalui Online Shop. Yogyakarta, E-journal Universitas Atma Jaya Yogyakarta. 9

Marwick, Alice \& Rebecca Lewis (2017). Media Manipulation and Disinformation Online. New York, Data and Society

Neke, Defriatno (24 Juli 2017). Wali Kota Baubau Laporkan Warganya ke Polisi gara-gara Status di Facebook.https://regional.kompas.com/read/2017/07/24/17414381/wali-kotabaubau-laporkan-warganya-ke-polisi-gara-gara-status-di-facebook. Akses 22 September 2018

Rusmana, Agus (2015). Penipuan dalam Interaksi Melalui Media Sosial. Bandung, Jurnal Kajian Informasi dan Perpustakaan. 3

Sidabukke, Sudirman (2009). Penyimpangan Hukum Kasus Prita Mulyasari. Surabaya, repository.ubaya.ac.id. 2 
Sidharta Gunawan, Yongki \& Zefania Ritonga, Rena (11 Juli 2016). Batasan antara Kebebasan Berpendapat dan Pencemaran Nama Baik Pada Media Sosial Dipandang dari segi Hukum. Surabaya,https://www.slideshare.net/YongkiSidhartaGunawa/fullpaperbatasan-antarakebebasan-berpendapat-dan-pencemaran-nama-baik-pada-media-sosial-yongki-dan-rena. 9-11

Tribunnews. (21 Oktober 2013). Tim Polda Babel Ringkus Empat WNA Kasus Penipuan Lewat Internet.http://m.tribunnews.com/regional/2013/10/21/tim-polda-babel-ringkus-empat-wnakasus-penipuan-lewat-internet, akses 22 Januari 2018. 